\title{
Reply to the Letter-to-the-editor by Matthias Rossbach regarding article Atomic and isotopic changes induced by ultrasounds in iron by G. Albertini et al. DOI: 10.1007/s10967-014-3341-5
}

\author{
Zsolt Revay
}

Published online: 13 March 2015

(C) Akadémiai Kiadó, Budapest, Hungary 2015

Dear Dr. Rossbach,

Editors normally do not reply to the letters-to-the-editors. They are forwarded to the corresponding authors, and then their reply and the letter are published together, if possible, immediately after the paper in question. In this case, we have not received any reply from the authors. The Journal of Radioanalytical and Nuclear Chemistry, for whose scientific content I am responsible, has been addressed in your letter, too; so I decided to make an exception and reply.

First of all, I thank you for sending us your critical comments. I fully agree with everything you wrote. This paper should not have been accepted in this journal. I have to admit that a procedural mistake has happened. I had serious doubts when I first saw the manuscript, but I also wanted to see the opinions of experts of the techniques used. Unexpectedly, the obvious mistakes listed by you were not addressed during the review procedure. The revisions requested were done and the manuscript was handled in the normal fashion. It slipped through my fingers.

Last year, we have been working on the improvement of our protocol. We try to do our best to keep the high standards through appropriate quality control, but human errors can happen. We have learned our lesson, and we have further improved our protocol to minimize the chance of such oversights. Discussion remains very important in science. We in the Journal of Radioanalytical and Nuclear Chemistry have always given all the opportunities for scientific discussions during the whole procedure starting with submission, even after publishing, and we are going to maintain this tradition.

Thanking you,

Zsolt Revay

Editor-in-Chief

This is Reply by Editor to Letter to Editor doi:10.1007/s10967-0153964-1.

Z. Revay $(\bowtie)$

Technische Universität München, Forschungsneutronenquelle

Heinz Maier-Leibnitz (FRM II), Garching, Germany

e-mail: JRNCeditor@gmail.com 